\title{
Repair of iatrogenic furcal perforation with glass ionomer cement
}

\author{
Sultana Parveen, Mozammal Hossain, Md. Abdul Hannan Sheikh and Md. Joynal Abdin
}

\begin{abstract}
Article Info
Department of Conservative Dentistry and Endodontics, Faculty of Dentistry, Bangabandhu Sheikh Mujib Medical

University, Shahbag, Dhaka, Bangladesh

For Correspondence:

Mozammal Hossain

hossainresearch@hotmail.com

Received:

Accepted:

Available Online:

2 September 2017

12 January 2018

7 March 2018
\end{abstract}

ISSN: 2224-7750 (Online) 2074-2908 (Print)

DOI: 10.3329/bsmmuj.v11i1.35548

Keywords:

Furcal perforation; Glass ionomer cement; Periodontitis

Cite this article:

Parveen S, Hossain M, Sheikh MAH, Abdin MJ. Repair of iatrogenic furcal perforation with glass ionomer cement. Bangabandhu Sheikh Mujib Med Univ J. 2018; 11: 70-74.

Copyright:

The copyright of this article is retained by the author(s) [Atribution CC-By 4.0]

Available at:

www.banglajol.info

A Journal of Bangabandhu Sheikh Mujib Medical University, Dhaka, Bangladesh

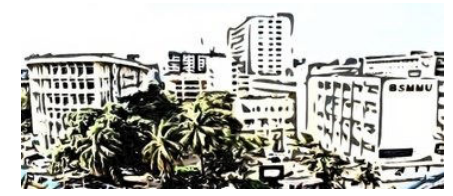

\section{Presentation of Case}

Dr. Sultana Parveen: A 28 year old male patient came to the outpatient Department complaining of discomfort on his lower right first molar tooth during mastication for one month. The patient also stated that he had received dental treatment on the lower right side three months back. Clinically, the tooth appeared sound but there was poor coronal filling of the affected tooth and the pocket depth was within normal range (Figure 1A,B). When the pulp vitality test was performed, it responded negatively. However, percussion pain was present. It seems that due to iatrogenic mishaps, chronic periodontitis could be developed in this case.

Dr. Mozammal Hossain: Radiograph showed periapical radiolucency $<1 \mathrm{~mm}$ on the apex of tooth and the floor of the pulp chamber was found perforated. However, there was no vertical or horizontal bony defect around the furcation or around the root apex. There was no sign of periapical lesion (Figure 1C).

\section{Treatment Procedure}

Dr. Parveen: In the first visit, following isolation of tooth with a cotton roll, the existing temporary filling was removed and a cotton pellet in the pulp chamber was found into the cavity. There was no bleeding into the three root canals but the working length measuring $\mathrm{X}$-ray view indicated a perforation in the furcal area. Dry cotton was placed into the pulp chamber and then closed with temporary filling by zinc oxide eugenol cement.

In the next visit, following removal of the temporary filling, the pulp chamber was flushed with normal saline. After drying the pulp chamber, the files were placed well into the canals, through the access cavity, to keep patency during the repair procedure. The perforation site was then sealed with light cure glass ionomer cement after conditioning with dentin conditioner (GC Corporation, Japan). After curing of the glass ionomer cement with light, the files were removed. The canals were prepared and irrigation of the canals was done with sodium hypochlorite solution. The canals were dried and filled with calcium hydroxide. Then the pulp chamber was closed.

After one week, the canals were rinsed and dried. As the tooth was symptom free, the root canals were then obturated with gutta percha cone and zinc oxide eugenol sealer by using lateral condensation technique. Cavity was filled with glass ionomer cement. Final X-ray was taken (Figure 1D,E,F). The patient was advised to follow-up.

\section{Provisional Diagnosis}

Iatrogenic furcal perforation

\section{Differential Diagnosis}

Dr. Parveen: Differential diagnosis may be chronic periodontitis, root caries, root resorption, granulation tissue formation. All these are excluded by earlier attempted dental treatment history, clinical and radiological examination. Furcal perforation can occur at any stage while performing endodontic therapy that is during access cavity preparation or during instrumentation or due to pathological condition such as caries, resorption. The result is a chronic inflammatory reaction of the periodontium that can lead to irreversible loss of attachment or loss of the tooth.

\section{Root caries and resorption}

Previous studies have indicated that root resorption and caries are the common causes for non -iatrogenic perforation. 1,2 However, when iatrogenic root perforations occur, it causes serious complications. $3-5$ As infectious process started at the perforation site (e.g. either from the root canal or from periodontal tissues), it impairs the healing as well as initiates an inflammatory process which exposes the supporting tissues to infection, pain and suppurations. In chronic conditions, it may lead to abscess, fistulae and resorption of bone, thus making prognosis for the treatment questionable leading to extraction of the affected tooth. $\underline{6-8}$ Therefore, it is consi- 


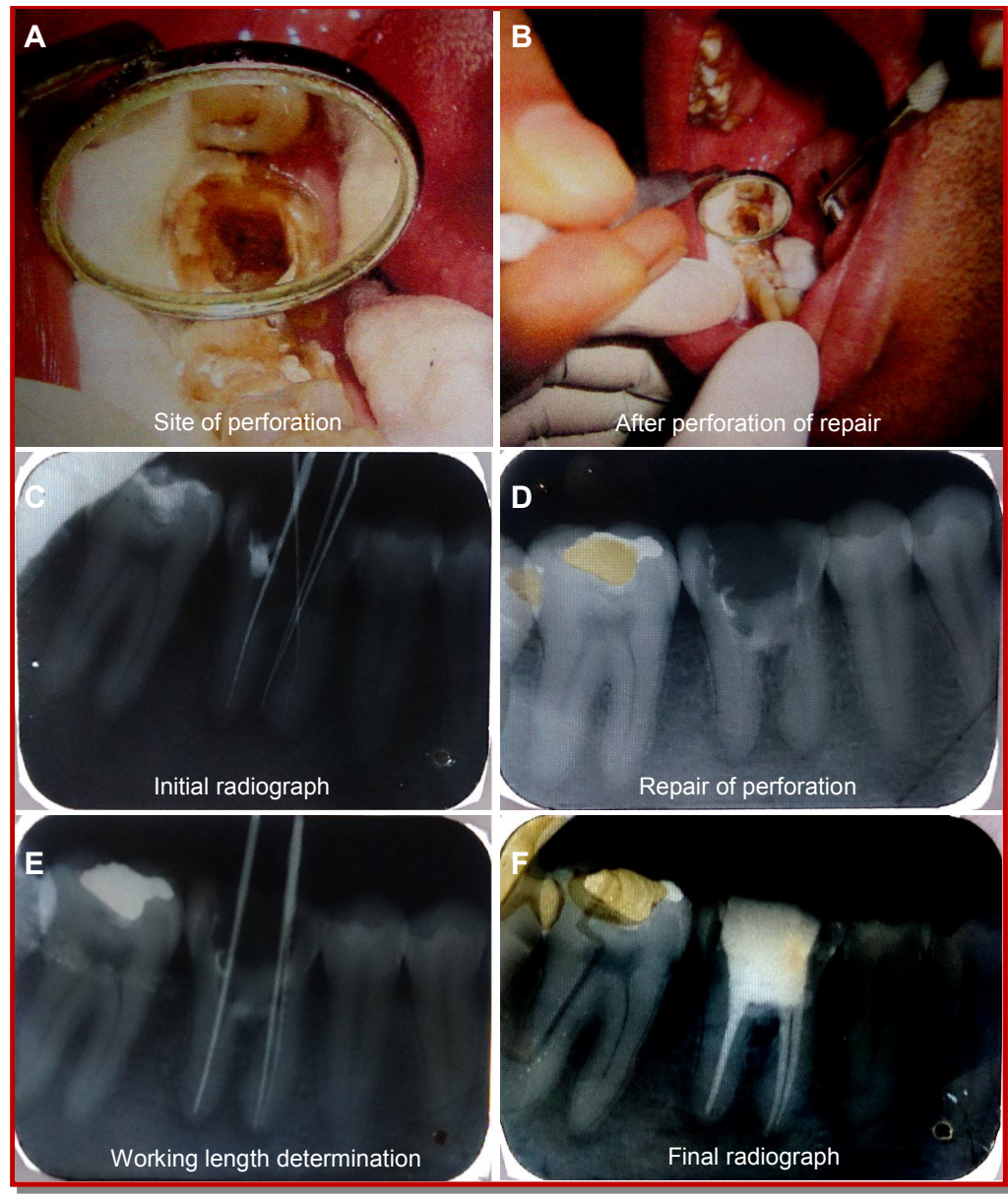

Figure 1: Clinical (A, B) and radiological photographs (C-F) of the case

dered that early diagnosis with appropriate management of the perforation will lead to longterm survival of the tooth.

\section{External root resorption}

External root resorption can be found in the furcation area of mandibular teeth as a result of chronic inflammation. $.9,10$ As the radiolucent image is poorly delimited and departs from the well-delimited furcation involvement restricted to bone, it is considered as a consequence of periodontitis. $\frac{9,10}{10}$ Therefore, the careful interpretation of the clinical and radiographic signs can assist the clinician to differentiate the diagnosis of root resorption in the furcation area from furcation involvements that result from periodontitis.

\section{Chronic periodontitis}

The loss of attachment that occurs as a result periodontitis ultimately reaches the furcal area of multirooted teeth.11,12 Attachment loss both in vertical and horizontal directions, frequently giving rise to lesions with complex bone topography. Perforation may also occur during non-surgical root canal treatment or during cavity preparation for restorative procedures. $\underline{11}$ The result is a chronic inflammatory reaction of the periodontium which is characterized by the formation of granulation tissue. This condition may lead to the irreversible loss of attachment or loss of the tooth.12

\section{Dr. Parveen's Diagnosis}

Iatrogenic furcal perforation

\section{Discussion}

Dr. Parveen: During endodontic treatment, procedural accidents usually affect the root canal therapy. A major complication of endodontic and restorative treatment is the accidental perforation of the root or the pulp chamber floor. Perforation is managed by surgically or non-surgically, depending on the particular characteristics of the case. $\underline{13}$ The prognosis may be questionable, if the treatment involves a lesion occurring at the level of the radicular furcation, but the prognosis is usually good if the problem is diagnosed correctly and treated with material having suitable sealing ability and biocompatibility. The prognosis also depends on the location, size and time of contamination of the lesion. $\underline{14}$

A furcal perforation refers to a mid curvature opening into the periodontal ligament space and a worst possible outcome in the root canal treatment. A perforation of the furcation is generally one of two types: a) the direct or b) stripping type. Each is created and managed differently and the prognosis varied on the site of perforation. The direct perforation usually occurs during identification of canal orifice. It is more often occurred with a bur and therefore, it is usually accessible and may be small and have walls. This type of perforation should be immediately (if possible) repaired with calcium hydroxide (dycal), glass ionomer, composite or MTA in an attempt to seal the defect.15-17 Prognosis is usually good if the defect is sealed immediately. Furthermore, in case of perforation repair, hemostasis is needed to control that makes the area dry so that optimal placement of restorative material can be accomplished. Material which can be used as hemostatic include calcium hydroxide, calcium sulfate and freezed dried bone. $\underline{\text { 18-21 }}$

\section{Assessment of perforation site}

Dr. Md. Abdul Hannan Sheikh: Perforation may occur in any area of tooth and can be divided according to the time such as: a) preoperative occurrences, typically pathologically such as resorption or decay, b) per-operative procedural accidents such as during access or canal instrumentation, c) postoperative procedural errors, e.g. during preparation 
of a post-space. According to Kvinnsland et al. (1989) $153 \%$ of the iatrogenic perforation occur during insertion of posts and the remaining $47 \%$ are induced during the routine endodontic treatment. In $73 \%$ of all cases, the complications occur in the maxilla and the remaining $27 \%$ occur in the mandibular arch. Adequate care is, therefore, needed to identify and dimensions of the pulp chamber as well as the anatomical variations of the specific tooth treated in order to prevent complications. Kvinnsland et al. (1989)1 also found that in maxillary anterior teeth, all perforations were located at the labial root aspect due to the operator's underestimation of the palatal root inclination in the upper jaw. In multi-rooted teeth, furcal perforations can occur when removing dentin from the chamber floor during searching for canal orifices. $\underline{22}$ The crown of many teeth is fre-quently perforated when the anatomical variations are not anticipated during access preparation as a result of misdirection of the bur with the long axis of the root.

\section{Radiological discussion}

Dr. Hossain: Careful examination of radiograph is important to evaluate the shape and depth of the pulp chamber and width of the furcation floor. $\underline{23}$ Furthermore, significant crown-root angulations, calcifications of the pulp chamber and orifices, anatomical variations, misidentification of canals and excessive removal of coronal dentin are often the reason for perforations in the coronal part of the tooth.

\section{Discussion on furcal repair}

Dr. Md. Joynal Abdin: The first clinical appearance of a perforation frequently demonstrates profuse bleeding from the injured side and persistent pain on percusion. $.24,25$ Multiple, angulated radiographs including bitewing radiographs are also essential for accurate diagnosis. $\underline{26}$ The aim of perforation management is to maintain healthy periodontal tissues against the perforation without persistent inflammation or loss of periodontal attachment. 27,28 Successful perforation repair depends on the ability to seal the perforation and re-establish a healthy periodontal ligament with adequate root canal sealing. $\underline{13}$

\section{Follow-up}

Dr. Parveen: The prognosis of teeth with perforations depends on the severity of the initial damage to the periodontal tissues, prevention of bacterial infection of the perforated site, the size of the perforation, the location of the perforation in relation to the gingival sulcus, the time lapse between injury and repair, the adequacy of the perforation seal, the sterility of the perforation, subjective factors such as the technical competence of the dentist and the attitude and oral hygiene of the patient and the biocompatibility of the material used to repair the perforation.29-36 In the past, many materials were advocated for perforation repair, however none provided a favorable environment for re-establishing the normal architected and pre detectable healing after treatment. The inadequacy of this material can be attributed to their inability to seal the communication between the oral cavity and the underlying tissues, or their lack of biocompatibility.

Dr. Shirin Malek: What is the present condition of the patient?

Dr. Parveen: In the present case, periapical radiograph revealed furcal perforation of the right lower first molar. The prognosis was deemed favorable in view of the short time since perforation (less than one month).

Dr. Boby Saha: What about the surgical and nonsurgical treatment?

Dr. Parveen: If feasible, non-surgical repair of the furcation perforation is preferred to surgical alteration of the tooth. The repair is difficult because of potential problems with visibility, hemorrhage control, and management and sealing ability of the repair materials. In general, perforations occurring during the access preparation should be sealed immediately, but the patency of the canals must be protected. Immediate repair of the perforations offers the best results for perforation repair.

Dr. Tasnim Wakia: Which materials can be used for perforation repair?

Dr. Parveen: Good success rate can be obtained the sealing ability and biocompatibility of the material. The choice of materials are zinc free amalgam, zinc oxide eugenol cement calcium hydroxide, gutta percha, glass ionomer cement, light cure glass ionomer cement, IRM, super EBA, and plaster of paris, resin modified glass ionomers and MTA for perforation repair, specifically when there is communication between the perforation site and oral cavity. $.37-39$ In the present case, light cure glass ionomer cement was chosen because it is a small particle, hydrophilic, non aqueous resin combined with a photo initiator and glass powder formulation.

Dr. Kamrun Naher Shomi: What are the advantages of using glass ionomer cement?

Dr. Parveen: The advantages of this material are its insolubility in oral fluid, reasonable adhesion to tooth structure, high strength and dual cure properties. Light cure glass ionomer offers the following attributes: Low cure shrinkage, low thermal expansion and extended fluoride release as found in traditional glass ionomer. $\frac{37-39}{\text { Regarding biocompa- }}$ bility of this material, Dragoo demonstrated clinically and histologically the biocompatibility of this restorative material. $\underline{40}$ The formation of an 
epithelial and CT adherence to light cured glass ionomer represents a significant advancement in its ability to restore previously considered hopeless teeth. The release of fluoride from light cured glass ionomer may positively affect bacterial plaque biochemistry through as alteration of carbohydrate metabolism as the material polymerizes with visible light, its setting is fast and controllable, thus improving performance and reducing messy handiling. 38,39 On the other hand, MTA has an excellent setting time and requires careful handling. Economically the glass ionomer material has a significant advantage over MTA.

Dr. Nushrat Saki: What are the factors that affect the prognosis of furcal repair.

Dr. Parveen: Factors affecting the successful outcome of perforation treatment depends on the bacterial contamination at the site of perforation which is needed to be prevented or eliminated.22 Various factors such as time from the perforation to detection, size, and shape of the perforation and also its location have a great importance to control infection at the perforation site.

Dr. Nargis Akhter: Has there any relation of healing with time of perforation?

Dr. Parveen: Regarding time of perforation repair, previous studies have reported that healing response was more clear when perforations were repaired immediately and an increase in tissue damage was found in the untreated perforations and in those teeth where the sealing of perforation was delayed. $37-39$ Another study indicated that healing response is more clear when the perforation repair is done as soon as possible. $\underline{40}$

Dr. Hossain: It can be concluded that perforation is severe complication which lower the prognosis of endodontic procedure. Treatment can be challenging and sometimes requires creativity. To best determine the long-term prognosis, the dentist must monitor the patient's symptoms, radiographic changes and most importantly, periodontal status. Radiographs and periodontal probing during recall examination are the best measures of success or failure of the repair procedure.

\section{Final Diagnosis}

Iatrogenic furcal perforation

\section{References}

1. Kvinnsland I, Oswald RJ, Halse A, Grønningsaeter
AG. A clinical and roentgenological study of 55 cases of root perforation. Int Endod J. 1989; 22: 7584.

2. Nicholls E. Treatment of traumatic perforations of the pulp cavity. Oral Surg Oral Med Oral Pathol. 1962; 15: 603-12.

3. Abou-Rass M, Frank AL, Glick DH. The anticurvature filing method to prepare the curved root canal. J Am Dent Assoc. 1980: 101: 792-94.

4. Eleftheriadis GI, Lambrianidis TP. Technical quality of root canal treatment and detection of iatrogenic errors in an undergraduate dental clinic. Int Endod J. 2005; 38: 725-34.

5. Sinai IH. Endodontic perforations: Their prognosis and treatment. J Am Dent Assoc. 1977; 95: 90-95.

6. Brezniak N, Wasserstein A. External apical root resorption. Am J Orthod Dentofacial Orthop. 2018; 153: 5-6.

7. Marques NC, Lourenco Neto N, Oliveria TM. Immediate and mediate furcal perforation treatment in primary molars: 24-month follow-up. Eur Arch Pediatr Dent. 2016; 17: 489-94.

8. Kerner S, Bronnec F. Conservative treatment of a large facial midroot perforation. Case Rep Dent. 2015 (in press).

9. Ghafoor R, Tabassum S, Hameed MH. Management of extensive external apical root resorption leading to root perforation. BMJ Case Rep. 2017 (in press).

10. Patel S, Foschi F, Mannocci F, Patel K. External cervical resorption: A three-dimensional classification. Int Endod J. 2008; 51: 206-14.

11. Tsesis I, Fuss Z. Diagnosis and treatment of a accidental root perforation. Endod Top. 2006; 13: 95 $-107$.

12. Al-Daafas A. Al-Nazhan S. Histological evaluation of contaminated furcal perforation in dogs' teeth repaired by MTA with or without internal matrix. Oral Surg Oral Med Oral Pathol Oral Radiol Endod. 2007; 103: 92-99.

13. Roda RS. Root perforation repair: Surgical and non surgical management. Pract Proced Aesthet Dent. 2001; 13: 467-72

14. Fuss Z, Trop EM. Root perforation, classification and treatment choice based on prognostic factors. Endod Dent Tramatol. 1996; 12: 255-64.

15. Bogaerts P. Treatment of root perforations with calcium hydroxide and Super EBA cement: A clinical report. Int Endod J. 1997; 30: 210-19.

16. Pace R, Giuliani V, Pagavino G. Mineral trioxide aggregate as repair material for furcal perforation: 
Case series. J Endod. 2008; 34: 1130-33.

17. Singh P, Paul J, Al-Khuraif AA, Vellappally $\mathrm{S}$, Halawany HS, Hashim M, Abraham NB, Jacob V, Thavarajah R. Sealing ability of mineral trioxide aggregate, calcium phosphate cement, and glass ionomer cement in the repair of furcation perforations. Acta Medica (Hradec Kralove). 2013; 56: 97-103.

18. Blumenthal NM. The use of collagen membranes for guided tissue regeneration. Compend Conpendium. 1992; 13: 214-18.

19. Sottosanti J. Calcium sulfate: A biodegradable and biocompatible barrier for guided tissue regeneration. Compendium 1992; 13: 226-28.

20. Kim S, Rethnam S. Hemostasis in endodontic microsurgery. Dent Clin North Am. 1997; 41: 499511.

21. Arens DE. Torabinejad M. Repair of furcal perforation with mineral tri oxide aggregate: Two case reports. Oral Surg Oral Med Oral Patho Oral Radidol Endod. 1996; 82: 84-88.

22. Kvinnsland I, Oswald RJ, Halse A, Grønningsaeter AG. A clinical and roentgenological study of 55 cases of root perforation. Int Endod J. 1989; 22: $75-$ 84.

23. Cosme-Silva L, Carnevalli B, Sakai VT, Viola NV, Franco de Carvalho L, Franco de Carvalho EM. Radicular Perforation Repair with Mineral Trioxide Aggregate: A Case Report with 10-Year Follow-up. Open Dent. 2016; 30: 733-38.

24. Tsesis I, Fuss Z. Diagnosis and treatment of an accidental root perforation. Endod Top. 2006; 13: 95 $-107$.

25. Alhadainy HA, Himel VT. An in vitro evaluation of plaster of paris barriers used under amalgam and glass ionomer to repair furcation perforation. J Endod. 1994; 20: 449-52.

26. Bryan EB, Woollard G, Mitchell WC. Nonsurgical repair of furcal perforations: A literature review. Gen Dent. 1999; 47: 274-78.

27. Tsutumachi T, Honda K. A new cone beam computerized tomography system for use in endodontic surgery. Int Endod J. 2007; 40: 224-32.

28. Torabinejad M, Higa RK, McKendry DJ, Pitt Ford. Dye leakage of four root end filling materials: Effects of blood contamination. J Endod. 1994; 20:
159-63.

29. Pitt Ford TR, Torabinejad M, Mckendry DJ, Hong $\mathrm{CU}$, Kariyawasam SM. Use of mineral trioxide aggregate for repair of furcal perforation. Oral Surg Oral Med Oral Radiol Endod. 1995; 79: 756-63.

30. ElDeeb ME, ElDeeb M, Tabibi A, Jensen JR. An evaluation of the use of amalgam, Cavit and calcium hydroxide in the repair of furcation perforation. J Endod. 1982; 8: 459-66.

31. Aguirre R, elDeeb ME, elDeeb ME. Evaluation of the repair of mechanical furcation perforations using amalgam, gutta-percha or indium foil. J Endod. 1986; 12: 249-56.

32. Balla R, LoMonaco CJ, Skribner J, Lin LM. Histological study of furcation perforations treated with tricalcium phosphate, hydroxylapatite, amalgam and Life. J Endod. 1991; 17: 234-38.

33. Nicholls E. Treatment of traumatic perforations of the pulp cavity. Oral Surg Oral Med Oral Pathol. 1962; 15: 603-12.

34. Lantz B, Persson PA. Periodontal tissue reactions after root perforation in dog's teeth. A histologic study. Odontol Tidskr. 1967; 75: 209-37.

35. Frank AL. Resorption, perforations and fraxtures. Dent Clin North Am. 1974; 18: 455-87.

36. Oswald RJ. Procedural accident and repair. Dent Clin North Am. 1979; 23: 593-616.

37. Jew RC, Weine FS, Keene JJ, Smulson MH. A histologic evaluation of periodontal tissues adjacent to root perforations filled with cavit. Oral Surg Oral Med Oral Pathol Oral Radiol Endod. 1982; 54: 12432.

38. Shomi K, Hossain M, Alam MS. Clinical and radiological evaluation of furcal perforation repaired by mineral trioxide aggregate and intermediate restorative material. Bangabandhu Sheikh Mujib Med Univ J. 2017; 10: 70-75.

39. Scherer W, Dragoo MR. New subgingival restorative procedure with geristore resin ionomer. Pract Periodontics Aesthet Dent J. 1995; 7: 1-4.

40. Dragoo MR. Resin-ionomer and hybrid-ionomer cements: Part II. Human clinical and histological wound healing responses in specific periodontal lesion. Int J Periodontics Restorative Dent. 1997; 17: $75-87$. 